\title{
ТРАДИЦИИ И ИННОВАЦИИ В МЕТОДИКЕ ПРЕПОДАВАНИЯ АНГЛИЙСКОГО ЯЗЫКА В ВЫСШЕЙ ШКОЛЕ
}

\section{TRADITIONS AND INNOVATIONS IN THE METHODOLOGY OF TEACHING ENGLISH IN HIGHER SCHOOL}

\section{N. Pokrovskaia}

Summary: The article deals with the main traditional and innovative trends in the modern development of the foreign language training system in the Russian higher education. It considers the foreign language communicative competence as a necessary component of the professional competency of students, a variety of foreign languages studied, specifics of teaching students English as the language of international communication, the system of foreign language training at university as a part of continuous language education in the life-long education model, diversification of programs in teaching English. The author pays special attention to the traditional (project method) and innovative (collaborative student learning) methods of teaching English.

Keywords: foreign language communicative competence, training in foreign languages at university, project, project activity, startup, collaboration, collaborative learning.

\author{
Покровская Наталья Владимировна \\ К.ю.н., Казанский (Приволжский) \\ федеральный университет \\ natasha.pokrrovskaia@gmail.com
}

Аннотация: В статье рассмотрены основные традиционные и инновационные тенденции современного развития системы подготовки по иностранному языку в высшей школе, включающие рассмотрение иноязычной коммуникативной компетенции как необходимого компонента целостной профессиональной компетентности студентов; разнообразие спектра изучаемых языков; учет специфики обучения английскому языку как языку международного общения; позиционирование системы подготовки по иностранному языку в высшей школе как компонента непрерывного языкового образования в модели life-long education; диверсификацию образовательных программ подготовки студентов по английскому языку. Особое внимание автор уделяет традиционным (методу проектов) и инновационным (коллаборативному обучению студентов) методам преподавания английского языка.

Ключевые слова: иноязычная коммуникативная компетенция, система подготовки по иностранному языку высшей школе, проект, проектная деятельность, стартап, коллаборация, коллаборативное обучение.

Система подготовки студентов по иностранному языку в высшей школе представляет собой совокупность соответствующих компонентов содержания обучения иностранному языку, в том числе в профессиональных целях, а с процессуальной точки зрения - совокупность и последовательность реализуемых этапов такой подготовки, нацеленных на формирование у студентов требуемого ФГОС уровня владения иностранным языком.

Проблема формирования иноязычной коммуникативной компетенции студентов актуализируется в настоящее время повышающимися требованиями к готовности выпускников вузов осуществлять профессиональную деятельность на высоком уровне, в том числе с использованием иностранного языка. Научный дискурс исследований данного направления, по мнению Т.Ю. Поляковой, может быть представлен в виде следующих основных тенденций [6, с. 9-12]:

1. иноязычная коммуникативная компетенция позиционируется как важнейший компонент целостной профессиональной компетентности студентов, что предполагает профессионально ориентированную специфику подготовки студентов по иностранному языку;

2. гарантия разнообразия спектра изучаемых языков в системе подготовки студентов в высшей 
школе через популяризацию изучения других иностранных языков, помимо английского, а также через реализацию программ дополнительного профессионального образования, в частности по обучению второму иностранному языку, редким иностранным языкам и иностранным языкам, необходимым для тех или иных отраслей российской экономики;

3. учет специфики обучения английскому языку как языку международного общения;

4. позиционирование системы подготовки по английскому языку в высшей школе как компонента непрерывного языкового образования в модели life-long education и опора на курс иностранного языка, который студенты освоили в рамках школьной программы;

5. диверсификация образовательных программ подготовки студентов по иностранному языку в вузе и учет потребностей разных групп студентов - бакалавров, магистров, аспирантов и др. и специфики изменений в использовании иностранного языка в профессиональной деятельности.

Данные тенденции учитываются при реализации образовательного процесса обучения английскому языку в высшей школе, который проектируется на основе комплекса традиционных и инновационных методов.

Следует отметить, что важный сегмент в системе подготовки студентов по иностранному языку в вузе занимает проектная деятельность, в частности подготовка студентов к участию в международной проектной деятельности. Кратко рассмотрим этапы работы с проектами [5, с. 102-104].

\section{1. Организационно-подготовительный этап}

На данном этапе преподаватель организует подготовку к выполнению проекта и презентации его результатов, к примеру, в виде дискуссии: идет повторение и закрепление лексических единиц по теме и выражений для ведения дискуссии:

Introducing a topic: Someone told me that..., I read somewhere recently that..., Did you know that?

Expressing concern: Oh, that's terrible! Really? That's a bit worrying. That sounds quite serious.

Для формулирования темы проектной деятельности преподаватель может использовать метод создания проблемной ситуации, к примеру, следующей:

Look at the diagram. Which of these problems does our country face? deforestation, extinction of animals, soil erosion, ozone depletion, loss of biodiversity, depletion of natural resources, global warming, greenhouse effect, acid pollution.

Далее преподаватель формулирует проблему проекта: If people cared more about the environment, the world would be a better place to live in.

Студенты осуществляют поиск информации по проблеме, работают в группах и готовят презентацию результатов проектной деятельности.

\section{2. Операционально-деятельностный этап}

На этом этапе идет работа студентов с информацией по проблеме и инициируется ее обсуждение, например, в формате двух групп, представляющих аргументы «за» и «против». Особое внимание преподавателю нужно обратить на способы аргументации студентов и сопровождение каждого аргумента примерами из жизни, литературы, фильмов и т.д. Примеры могут быть продемонстрированы на доске, интерактивной доске в виде статистики, графиков, фрагментов фильма, видео и др. Обсуждение результатов проектной деятельности организуется и регулируется модератором - преподавателем или подготовленным студентом в соответствии с программой обсуждения.

\section{3. Оченочно-результативный и рефлексивный этапы}

После окончания проектной работы осуществляется оценка хода самой работы и возникших трудностей, выявляются причины их появления, анализируются использованные речевые средства и адекватность их включения в речь при презентации результатов проекта в зависимости от ситуации общения. Рефлексия может быть проведена в виде самоотчетов студентов, выполненных в произвольной или ориентированной на вопросы форме. Во втором случае преподавателю необходимо составить список направляющих вопросов.

Инновационной моделью подготовки студентов к международной проектной деятельности является модель стартапов.

Разработка стартапа (startup - «начинающая фирма, ввод в действие» - пер. с англ.) является одной из актуальных задач развития современного инновационного образовательного пространства. Стартапы могут носить различную тематику и иметь вариативные направления. Во многих современных публикациях понятие стартапа рассматривается в качестве уникальной идеи, имеющей выход в сферу коммерциализации. Так, «ранее стартапом считалась фирма, которая предлагает совершенно новый продукт или услугу на рынке». 
На данном этапе развития образования произошли изменения, касающиеся переориентации на сферу реальной действительности. Современной системе образования необходим выход в другие плоскости жизни. Многие современные стартапы в различных областях знаний используют интернет-технологии для цифровизации результатов [3, с. 1-2].

Приведем несколько примеров стартапов. Платформой «Мел» были выбраны 5 лучших стартапов в сфере образования в онлайн-формате: BetterLesson, «Лекториум», Piazza, Technology Will Save Us, Mehackit.

Подход образовательного стартапа нацелен прежде всего на обеспечение образовательного процесса изучения английского языка посредством ИКТ-ресурсов с возможностью дистанционного обучения. Такой подход способствует автономизации процесса изучения английского языка, повышению компьютерной грамотности, а также соответствует настоятельному требованию современного этапа развития общества и образования цифровизации.

В системе подготовки студентов по иностранному языку в высшей школе можно предложить разработку стартапов профессионального наполнения, которое варьируется в зависимости от профиля их подготовки.

Структурно стартап должен содержать следующие основные компоненты, признанные на международном уровне:

The goal of the project

Objectives of the project

Why is ... relevant?

Bar chart with the results of the survey

How does it work?

Examples of ... and information contained

Russian and English translation of the project information

Does it have any potential?

The prospects of this project are the following ...

Содержанием стартапа могут быть проблемы, связанные с профилем подготовки студентов, к примеру, из сферы экономики, инженерной деятельности, менеджмента, маркетинга, дизайна и т.д. Ведущей концептуальной идеей организации проектной деятельности в формате подготовки проекта стартапа должна быть разработка инновационной идеи, направленной на повышение эффективности функционирования той или иной сферы производства, науки, искусства и др., которая имеет высокий потенциал для коммерциализации.

Инновационным направлением в методике преподавания английского языка в высшей школе является коллаборативное обучение, рассматриваемое Н.В. Павельевой как подход [4, с. 30-37], основной фунда- ментальной идеей которого является организация различных вариантов активного когнитивного поиска, обсуждения информации и дискуссии по ее содержанию, понимание ее смысла. Реализация данной идеи может происходить в форме выполнения групповых проектов, подготовки совместных семинаров, работы «вихревых групп» и др. Такая работа всегда растянута во времени и предполагает постоянный контакт студентов друг с другом и с преподавателем, который может успешно поддерживаться посредством онлайн-технологий [7, с. 37-43].

Анализ научных публикаций, связанных с проблемой актуальности создания системы коллаборативного обучения в вузе, позволяет обобщить сильные стороны коллаборативной образовательной среды: 1) преподаватель-фасилитатор организует образовательный процесс на основе принципов теории коллективной деятельности; 2) студенты получают положительный стимул для развития творческого потенциала, активно участвуя в деятельности, пропитанной, с одной стороны, духом сотрудничества и конкуренции с другой; 3) каждый студент имеет возможность для самовыражения, саморегуляции, самоорганизации, самооценки и рефлексии своей деятельности; 4) коллаборативное обучение формирует и совершенствует коммуникативные способности студентов, навыки самостоятельной деятельности, ведущей к эффективной социализации; 5) организация коллаборативного обучения способствует формированию критического мышления студентов и стимулированию преподавателя к активной творческой деятельности [8, c. 78-82].

В настоящее время существуют несколько моделей организации коллаборативного обучения иностранному языку на основе онлайн-технологий. Типологизация основана на средствах доставки учебных материалов. Наиболее распространенными являются онлайновые кейс-технологии, корреспондентское обучение, электронная образовательная среда, сетевое обучение.

Целевой доминантой коллаборативного обучения является формирование у обучающихся умений коллаборации в условиях взаимодействия, в том числе иноязычного речевого. В ходе совместного решения коммуникативной задачи реализуется языковое погружение в общий для всех общающихся коммуникативный контекст, который может моделироваться с использованием цифровых образовательных ресурсов и онлайн-технологий.

В рамках реализации коллаборативного обучения преподаватель может спроектировать структурированное или проблемно-ориентированное занятие. Оно в целом соотносится с технологией проблемного обучения, опирается на обучение в сотрудничестве, активное 
и коммуникативное взаимодействие между студентами и преподавателем, преобладающую самостоятельную деятельность студентов. В центре внимания находится проблемная ситуация [9].

Структура занятия такого типа состоит из трех методических блоков:

- в первом блоке осуществляется мотивирующее начало занятия, в том числе с использованием медиа-средств, ставится цель, вводится проблема, например, на основе заранее подготовленного доклада и происходит первое обсуждение brainstorming.

- во втором блоке осуществляется детальное обсуждение проблемы и поиск путей ее решения, анализ методов и средств, распределение обязанностей и заданий с указанием конечного продукта на выходе, например, постера или презентации, осуществляется работа с материалами - как индивидуально, так и в парах, и в группах - принимается решение, формируется окончательный продукт, обсуждается в группе и происходит возврат к изначальной гипотезе и постановке проблемы. Далее студенты анализируют, насколько эта гипотеза была доказана, проблема была решена, то есть осуществляется рефлексия.

- третий блок означает перенос приобретенных знаний и умений на новые ситуации. Здесь осу- ществляется усиленная практика в применении, как на основе рабочих конспектов, так и в ходе ролевых или деловых игр.

Для такого типа занятия очень важна коммуникативная составляющая, в частности так называемый управляемый учебный разговор, похожий на сократовский метод обучения, когда преподаватель и студенты в диалоге вместе ищут оптимальное решение.

Итак, система подготовки по иностранному языку в современной высшей школе функционирует в условиях внедрения новых подходов к проектированию и организации образовательного процесса, в том числе в условиях сочетания офлайн- и онлайн-обучения.

Реализация данной системы наиболее эффективна на основе импликации традиционных и инновационных подходов и методов преподавания, которые обеспечивают разработку новых методик и технологий обучения. Такое сочетание разных методов и форм обучения способствует тому, что в процессе проектной деятельности и коллаборативного обучения английскому языку групповая работа используется с целью приобретения необходимых навыков. Следовательно, создается ситуация «естественности учения», включающего социальное взаимодействие и творческую активность студентов, что способствует приобретению открытости, гибкости и свободы принятия решений.

\section{ЛИТЕРАТУРА}

1. Аниськович Н.Р. Корпоративное обучение учащихся речевому взаимодействию на уроках английского языка // Актуальные проблемы обучения иностранным языкам на современном этапе. Материалы международной научно-методической конференции, декабрь. - Мн.: 2000. - С. 22-24.

2. Бар Р., Таг Дж. От обучения к учению - новая парадигма высшего образования / Р.Бар, Дж.Таг // Университетское образование: от эффективного преподавания к эффективному учению. Сб. статей-рефератов по дидактике высшей школы // Белорусский государственный университет. Центр проблем развития образования. - Мн.: 2001. - С. 13-39.

3. Бекетова 0.А. Инновация в образовании: понятие и сущность // Теория и практика образования в современном мире: материалы V Междунар. науч. конф. (г. Санкт-Петербург, июль 2014 г.). - СПб.: Сатисъ, 2014. - С. 1-2.

4. Павельева Н.В. Коллаборативное обучение как модель эффективной организации образовательного процесса / Н.В. Павельева // Образование. Карьера. 0бществ0.-2010. - №3 (29). - С.30-37.

5. Полат Е.С. Метод проектов на уроках иностранного языка // Иностранные языки в школе. - 2000. - № 2-3. - С. 102-104.

6. Полякова Т.Ю. Основные направления развития системы подготовки по иностранному языку в неязыковых вузах // Вестник МГЛУ. Серия "0бразование и педагогические науки". - 2019. - Вып. 1(830). - С. 9-19.

7. Садыкова Г.В., Каюмова А.Р. Кросс-культурное коллаборативное онлайн обучение глазами студентов разных языковых общностей: кейс-исследование / Г.В. Садыкова // Открытое и дистанционное образование. - 2017. - № 3(67).- С. 37-43. D0I: 10.17223/16095944/67/6

8. Синицына Г.П. Стратегия обучения в партнерстве: Коллаборативное обучение / Г.П. Синицына // Педагогические науки. - 2019. - №2(36). - С. 78-82.

9. Тарханова И.Ю. Интерактивные стратегии организации образовательного процесса в вузе: Учебное пособие. Ярославль: Изд-во ЯГПУ, 2012. - 67 с.

\footnotetext{
(c) Покровская Наталья Владимировна (natasha.pokrrovskaia@gmail.com).

Журнал «Современная наука: актуальные проблемы теории и практики»
} 